\title{
Business model tooling: where research and practice meet
}

\author{
Harry Bouwman ${ }^{1}$ (D) $\cdot$ Mark de Reuver $^{1} \cdot$ Marikka Heikkilä $^{2} \cdot$ Erwin Fielt $^{3}$
}

Received: 6 May 2020 / Accepted: 6 May 2020 / Published online: 9 June 2020

(C) Institute of Applied Informatics at University of Leipzig 2020

\begin{abstract}
This special issue bundles a series of papers on business model tooling. Business model tools are methods, frameworks or templates to facilitate communication and collaboration regarding Business Model analysis, (re-)design, adoption, implementation and exploitation. In this introduction to the special issue, we position business model tooling in the broader literature, going beyond the mere use of tooling to disseminate academic knowledge. We point out the unique contributions on business model tooling that information systems scholars can bring. After giving an overview of business model tools and ontologies, we sketch a brief research agenda comprising seven research directions: (1) design of tooling; (2) interfaces and usability; (3) evaluation and testing; (4) adoption, diffusion and commercialization of tooling; (5) privacy and security of tool users; (6) the use of tooling in business model education; and (7) future tooling enabled by big data and machine learning.
\end{abstract}

\section{Introduction}

Over the years, Electronic Markets has built a tradition of high-impact research on Business Models (BM hereafter). A specific hallmark was the 1998 publication of the seminal paper by Timmers on Business Models for Electronic Markets (Timmers 1998). Since then, Electronic Markets has been at the forefront of BM research. In 2001, a timely special section was dedicated to BMs (Alt and Zimmermann 2001). In 2014, some of the key thought leaders on BM

This article is part of the Topical Collection on Business Model Innovation: Tools and Innovation patterns

Harry Bouwman

W.A.G.A.Bouwman@tudelft.nl

Mark de Reuver

G.A.deReuver@tudelft.nl

Marikka Heikkilä

marikka.heikkila@utu.fi

Erwin Fielt

e.fielt@qut.edu.au

1 Faculty of Technology, Policy and Management, TU Delft, Building 31, Jaffalaan 5, 2628, BX Delft, The Netherlands

2 School of Economics, University of Turku, Rehtorinpellonkatu 3, 20014 Turku, Finland

3 Science and Engineering Faculty, Information Systems School, Queensland University of Technology (QUT), Gardens Point, 2 George St, Brisbane, QLD 4001, Australia thinking were interviewed. Furthermore, publications regularly featured research and conceptual work on BM ontologies, patterns, and support systems. Also, papers were published on BMs for specific technologies, such as mobile applications, platforms and blockchain. As Electronic Markets contributed significantly to developing BM thinking, we are glad that, in this tradition, we can bundle papers on a specifically relevant topic: tooling for BMs.

\section{Positioning BM tooling in literature}

Business model tools can be seen as 'boundary objects' that facilitate exchanging business model ideas between stakeholders (Bouwman et al. 2018). We define BM tooling here as "the use of methods, frameworks or templates (here referred to as tools) to facilitate communication and collaboration regarding Business Model analysis, (re-)design, adoption, implementation and exploitation". In this section, we position BM tooling in the broader literature on BMs.

In general, BM research features in academic schools of strategic management (Zott and Amit 2007; Zott et al. 2011; Teece 2010; Wirtz et al. 2016), entrepreneurship research (Morris et al. 2005; Sosna et al. 2010; Onetti et al. 2012; George and Bock 2011), innovation management (Chesbrough and Rosenbloom 2002; Christensen et al. 2016) and information systems (Timmers 1998; Osterwalder 2004; Osterwalder et al. 2005; Osterwalder and Pigneur 2010; El Sawy and Pereira 2013). Strategic management and 
entrepreneurship have a strong orientation to developing theories that explain how BMs contribute to competitive advantage. In more theory-oriented streams of strategic management, practical recommendations are lacking (Zott and Amit 2007,2008 ) or remain mostly on a generic level. For instance, scholars recommend to conduct environmental scanning and create and implement action plans (Wirtz et al. 2010) or to consult colleagues to assess BMs and strengthen the BM to stay flexible (Weill and Woerner 2013). Others recommend experimenting, learning and keeping financial resources at hand to redefine BMs (Teece, 2010). However, actionable answers to how-to questions are often lacking.

The main assumption in strategic management appears that a theory in itself suffices to help managers to understand what to do in practice. However, managers often have a hard time translating knowledge from theories to their daily activities. Ironically, although BM thinking once originated from practice, current academic discourse in strategic management and entrepreneurship research on BMs is thus largely abstract, repetitive, and conceptually focussed, as reflected by the many states of the art, bibliometric studies and research agendas. The dominance of theory over practice reflects broader concerns on strategic management literature on its inward-looking nature and pre-occupation with rankings, impact and academic careers as recently addressed in the book by Tourish (2019) titled 'Management Studies in Crisis'.

Information systems (IS) and innovation management literature, in turn, take a more pragmatic approach on BMs. In these fields, scholars do not merely treat BMs as a strategic device, but also as a construct that is related to the business logic and business processes of organizations (Al-Debei and Avison 2010). In addition to contributing to the scientific debate, scholars in these fields also aim at providing means for managers to apply ideas from BM research in practice. For example, many articles discuss (re)design of BMs, and its implications on applications, databases and IT infrastructure of (networked) businesses.

Within IS, a notable research stream develops BM tooling that makes BM research practically usable, while going beyond templates or canvases based on BM ontologies. For instance, visual templates make ontologies like Canvas practically understandable. Similarly, card games with BM patterns help to bring alive the taxonomies and classifications from BM research in a specific domain.

In our view, however, BM tooling is not only a way to utilize scientific knowledge on BMs. BM tooling is also a research area in itself.

\section{BM tooling in IS literature}

In this section, we discuss two specific uses of BMs in IS research. For this, we build on ideas by Veit et al. (2014) who distinguish three streams of BM research in IS: (1) BMs for the ICT industry, (2) BMs and digital transformation, and (3) IT support for developing and managing BMs (Veit et al. 2014). The first mentioned research stream is a specific application domain of generic BM thinking and outside of the scope of this paper. Hence, we focus on the two latter streams.

$B M$ tooling and digital transformation In a digital economy, hardly any company can escape using IT in creating, delivering and capturing value. Moreover, due to digitalization, firms are embedded in increasingly complex networks or ecosystems, which requires analysing BMs of networks rather than individual organizations. Digitalization changes how incumbent firms operate with partners, even more so due to emerging technologies which span the boundaries of a single firm, such as Industry 4.0, IoT and blockchain.

Consequently, understanding how digitalization affects BMs requires an understanding of Enterprise Architectures (EA) (Lankhorst 2009; Jonkers et al. 2006; Versteeg and Bouwman 2006) both by incumbent firms as well as start ups that are connected with these incumbents, which model business processes, applications and IT infrastructure beyond the single firm. In turn, EA-thinking would benefit from more $\mathrm{BM}$-oriented research on value and information exchange within eco-systems to enable aligning processes in a networked enterprise. Although EA tools are extensive and some intermediate conceptualizations bridge the gap between BM and EA thinking (e.g. Solaimani et al. 2015, 2018), more work needs to be done to connect BMs with business modelling as practised in the EA domain. This is necessary to properly analyse and understand the interrelatedness of BMs and EA in networked businesses that operate in a digitalized world.

\section{IT support for developing and managing BMs}

To formalize business model representations and visualizations, various ontologies and decision-making tools are available. Multiple BM ontologies exist, which describe the core components or building blocks of a BM. Some ontologies describe the $\mathrm{BM}$ of a single organization, while others focus on a network or ecosystem of partners. The scope of ontologies differs as well, as some describe only the BM, while others also cover the technological architecture.

Given the plurality of existing BM ontologies, metamodels are increasingly needed. Meta-models describe the components as well as the architecture of a BM (Foss and Saebi 2017). Meta-models are helpful to (1) communicate, analyse and make decisions about BMs, (2) clarify which BM components to focus on, (3) develop and use BM tools to support BM design or BM innovation, (4) communicate about and integrate BM ontologies and (5) to describe specific BM archetypes or patterns (Fielt 2013). Ontologies as 
developed in the past, such as the Business Model Ontology (Osterwalder and Pigneur 2010; Osterwalder 2004), the STOF model (Bouwman et al. 2008), VISOR (El Sawy and Pereira 2013) and BM Cube (Lindgren and Rasmussen 2013), offer insights in what these components entails and how these are interrelated. There are also taxonomies, or frameworks for many classifications of components (e.g. Dubosson-Torbay et al. 2002; Morris et al. 2005; Onetti et al. 2012; Demil and Lecocq 2010; Lambert and Davidson 2013).

\section{BM tools, ontologies and meta-models}

Components are the building blocks for designing and innovating a BM. Given the various ontologies that exist, there is no agreement on the conceptual meaning of specific components or on which components are core and critical. Tooling that visualizes the components of BMs benefits both cognitive as well as experimental approaches, which can be real experiments or thought experiments on parallel business models. In both cognitive and experimental approaches to BM innovation, managers need to be aware that BM Innovation is an iterative and dynamic process, sometimes even following agile principals as known from IS research, and that BMs themselves are never static. Design or redesign steps are followed by implementation and management of the new or innovated BM.

Managing BMs in organizations requires visualisations of the BM across the business model lifecycle (from strategy conception to technical implementation) and requires that they are shared with a diverse set of stakeholders. After the exploration phase that encompasses both (re-) design and implementation, the phase of exploitation or "use of the BM" follows (Terrenghi et al. 2017; Wirtz and Daiser 2017). While transitioning from one phase to the next, minor (componentbased) or major (architectural) changes are still possible. An overview of visual representations of BM ontologies is provided by Täuscher and Abdelkafi (2017). Although these representations are in general static, in the field of BM and System Dynamics more dynamic models can be found (Abdelkafi and Täuscher 2016; Cosenz and Noto 2018).

In all phases of the use of BM ontologies, graphical (visual) or textual representations are helpful. In the paper of Johannes Schwarz and Christine Legner, they discuss how BM ontologies can function as boundary objects in overcoming knowledge boundaries between communities of practice (Schwarz and Legner 2020). These community of practice are, for instance, the decision board, BM experts, including academics, business owners and other stakeholders being actively involved in BM design and innovation. Shared use of common syntax, as well as common understanding on a semantical level, are key to make the right decision on a pragmatic level.

\section{Foci of BM tooling}

To position tools and their utility, it is important to note that different tools can be a) applied in different phases of designing and or innovating BMs, b) directed towards different stakeholder groups, c) based on different unit of analysis, and d) considering economic values and/or alternative values.

Tools can be applicable in all phases as is typical for BM ontologies promoting a common language or focus. Alternatively, tools can focus on a specific phase in the design or innovation process, like experimentation, implementation and management.

Furthermore, it is important to realize who the targeted audience is. For example, users of the tools can be communities of practice or functional teams active in operations, finance, or practitioners working in large enterprises or SMEs, incumbent or start-up firms. Moreover, nowadays, business models are also used by government organizations (e.g. Kuk and Janssen 2013). An important consideration is whether the BM tool is intended to serve a broader audience or if it is tailored to a specific research domain, for instance, BMs for sustainability, Smart Cities BMs, or Data-driven BMs.

Also, the unit of analysis plays a role in establishing how a tool can be used. In the CANVAs ontology, the firm is the initial unit of analysis, while in for instance the STOF ontology the starting point is the product-market combination, e.g. a product, service, service bundle or even unbundling of services, as reflected in the core value proposition. Similarly as in the STOF model, other BM ontologies, like VISOR or BM Cube, have a value network or business eco-system perspective. In these ontologies, it is assumed that BMs from multiple actors have to work out in concert with the core BM under study.

The unit of analysis relates also to a multi-level problem. BMs in a networked business environment, value network or ecosystem have to work out positively, not only for the focal firm but also for all involved actors, leading to additional requirements to the ontology or toolset. This is a common challenge in business networks, ecosystems and platform BMs. Another example of challenges regarding the unit of analysis is related to a firm that manages multiple alternative BMs. Reasons for multiple BMs are diversification (from a corporate perspective) and renewal (having established and new business models). This requires BM tools to support portfolio management of BMs, which is a still unexplored domain of research.

Last, we would like to draw attention to the forms of value BM creates, delivers and captures. Even though the value to the customer is characterised by how well the product helps to solve the customer's pains and gains, the value captured by the company is often assumed to be in the form of economic value. Yet, a recent and steady growing stream of literature focuses on ecological and sustainability as a value (Boons and 
Lüdeke-Freund 2013). This broadening of the scope of BM research towards sustainability draws attention to what we would label as multi-value BMs that pay attention to other values than economical, for instance, social innovations, inand exclusion, privacy and security.

\section{Other BM tools}

The use of tools is not straightforward. Practitioners often work on their BMs with tools that are not specifically designed for creating BMs. For instance, in our empirical research, we saw that the most often mentioned tools in BM Innovation processes were SWOT analysis and other strategy tools (Heikkilä and Bouwman 2018). SWOT, like PESTEL, originates from strategy design thinking. Also, scenario analysis, 5-forces (Porter 1980), partner selection (Cummings and Holmberg 2012) and Balanced Score Card (Kaplan and Norton 2008) have their roots in strategic management (see also Vuorinen et al. 2018 for an extensive overview of strategy tools). These tools are well known and broadly accepted but in essence not geared to BMs or BM Innovation per se.

Next to strategy focussed tools, there are tools specifically developed for BMs. In addition to the already mentioned BM ontologies and their visualizations, specific BM tools have been developed. For instance, BM stress-testing to test the robustness of a BM under different scenarios (Haaker et al. 2017); BM road mapping, to define alternative migration paths from an existing (as-is) to a future (to-be) BM (De Reuver et al. 2013; Hakkarainen and Talonen 2012); BM Viability radar to assess the viability of a BM by looking into the $\mathrm{BM}$, value network and regulations and standards (Heikkilä et al. 2015); or BM patterns (Remane et al. 2017). The latter is expanded into a hierarchical taxonomy as discussed in the contribution of Weking, Hein, Bohm and Krcmar (Weking et al. 2020). They make the overlap and relations between specific BMs explicit so that the patterns can support finding solutions for limitations to existing business models. In that sense, taxonomies enable a more systematic search process for related BM patterns. This approach is comparable to that of Taran et al. (2015) who uses $\mathrm{BM}$ process configurations to organize BMs and to the work of Chatterjee (2013) that focuses on taxonomies and migration paths. Both approaches are more systematic than, for instance, an alphabetic overview, or BM playing cards proposing BMs with well-known examples as used in brainstorm sessions. However, a more practical tool based on taxonomies (and the $\mathrm{BM}$ process configurations for that matter) is still to be developed further.

In general, tooling is used on a tool-by-tool basis rather than as comprehensive solutions addressing the business problems of practitioners. A notable exception is our tooling available from the businessmakeover.eu platform. We developed BM paths, a set of steps that we suggest the companies take when they are facing challenges in designing or innovating their BM. These paths were identified based on an extensive number of case studies (Heikkilä et al. 2018). Starting from a meta-model covering ideation via BM (re-)design, testing of new BMs, implementation and management of the BM, we developed an appealing user interface, based on what we labelled as "I want to" paths. Four core paths were developed: I want to start a business, to test my business, to grow my business, and to make my business more profitable (Heikkilä et al. 2018). The paths suggest a set of simple tools that can be used as a self-service or with the help of advisors. Of course, there are alternative portfolios of tools, for example, available from strategyzer.com or bmtoolbox.net.

Next to platforms that offer access to sets of tools, there are also dedicated software-based tools. For instance, Szopinski, Schoormann, Thomas, Knackstedt and Kundisch, discuss the functions of such tools, provide a classification and define a research agenda with a focus on functional requirement and performance of the tools, in combination with user and task characteristics (Szopinski et al. 2019). Daas et al. (2013), in an earlier issue of EM, developed a decision support tool for the financial assessment of a BM, based on the design of an integrated marketing research approach making use of conjoint analysis for a pricing model and real market data. Latora et al. (2018) developed a decision support tool for BM selection based on Analytical Hierarchy Process analysis. Ebel et al. (2016) describe how they developed a framework and built a tool for a collaborative BM development tool that support the $\mathrm{BM}$ design phases from environmental scanning via BM design, implementation and BM management in a large IT incumbent, making use of action design principals.

From the overview so far, it is clear that there are many tools available and that there is also an increasing number of taxonomies that are helpful for the further development of tools, while also specific tools are developed for collaborative work on BMs.

\section{Open research questions}

There are still several academic questions to be dealt with. Some questions worthwhile to study are for instance related to:

- Design questions: How to design tools that are based on sound research and deep insights into issues in BM design and innovation? How does research on tooling fit into (action) design science research? What can design science research offer to BM tooling research in terms of keeping $\mathrm{BM}$ tooling practice-oriented, while increasing rigour in the evaluation of meeting user requirements, efficiency and applicability? 
- The interface of the tools: How easy are BM tools to use and how can relevant data on the BM be accessed and stored? As mentioned before, the tools for some target groups need to be very simple. Simplicity is not only relevant from a usability perspective, but also from a pragmatic point of view. For instance, SMEs have limited time to reflect on their daily business and to reflect on their daily business. Using prefilled examples, making secured data storage possible, and offering support tools is key.

- The testing of the quality of tools: How are results validated, does a tool deliver the results as expected, are BM concepts, patterns, taxonomies as used or extracted from tools useful? What lessons can be learned? Which tools are more applicable seen specific seen the problem to be solved? For instance, Athanasopoulou and De Reuver discuss how the use of a variety of BM tools helps the process of finding a suitable service and market in situations of high uncertainty (Athanasopoulou and de Reuver 2020) ${ }^{1}$

- Adoption and diffusion of tooling, commercialization of tooling: Which tools and ontologies are favoured by advisors, users, experts, decision-makers and stakeholders? How can developed tools make the transition from research to practice? What are viable BMs for the commercialization of BM tooling themselves and how to deal with intellectual property?

- Privacy and security: Are data only accessible to users or are data also accessible, based on informed consent, for tool optimization or BM research? These issues are specifically relevant when online tools and platforms are used and both needs to be guaranteed.

- Using tools in BM education: What can be learned from student users? Does offering of tools, in entrepreneurship courses help students to opt for starting their own business? How can BM tooling be included in curricula, where there is less background knowledge on business topics?

- Future development of tools: How far can we extend the tooling approach? Can developing of business models (or some part of it) be automated - for instance using machine learning with repositories of business models, patterns, metrics, etc.? Or will tooling remain a mere supporting artefact, and the entrepreneur's capabilities for figuring out what opportunity to tackle will continue to be the most essential capability for BM innovation?

\section{Concluding remarks}

This special issue brings together several interesting papers on BM. BM tooling represents an increasingly mature research

\footnotetext{
${ }^{1}$ This paper has been handled by a regular editorial board editor of Electronic Markets to avoid any conflict of interest.
}

stream within IS. However, many research questions are still to be explored, including but not limited to those mentioned in this paper. At the same time, we strongly believe that tooling is essential to make scholarly BM work practically usable for managers.

Many generic, strategy and marketing tools, as well as BMspecific tools, are already available. To distinguish IS research as more practical and implementation focused in comparison to other disciplines that study BMs, we need to put more effort in (1) bridging the gap between BM thinking and technical implementation towards enabling information technology, and (2) systematically exploring and analysing the contribution that can be made by tooling to BM design and innovation research. At the same time, we are aware that the social side of $\mathrm{BM}$ implementation needs to be taken more into account, related to the role of leaders, communication about BMs, innovative culture and so on.

Acknowledgments The work by H. Bouwman, M. de Reuver and M. Heikkila was partly supported by funding from the European Community's Horizon 2020 Program (2014-2020) under grant agreement 645791 (Bouwman, De Reuver and Heikkila) and grant agreement 825225 (De Reuver). The content herein reflects only the authors' view. The European Commission is not responsible for any use that may be made of the information it contains.

\section{References}

Abdelkafi, N., \& Täuscher, K. (2016). Business models for sustainability from a system dynamics perspective. Organization \& Environment, 29(1), 74-96. https://doi.org/10.1177/1086026615592930.

Al-Debei, M. M., \& Avison, D. (2010). Developing a unified framework of the business model concept. European Journal of Information Systems, 19(3), 359-376. https://doi.org/10.1057/ejis.2010.21.

Alt, R., \& Zimmermann, H.-D. (2001). Preface: Introduction to special section - Business models. Electronic Markets, 11(1), 3-9. https:// doi.org/10.1080/10196780122955.

Athanasopoulou, A., \& de Reuver, M. (2020). How do business model tools facilitate business model exploration? Evidence from action research. Electronic Markets. https://doi.org/10.1007/s12525-02000418-3.

Boons, F., \& Lüdeke-Freund, F. (2013). Business models for sustainable innovation: State-of-the-art and steps towards a research agenda. Journal of Cleaner Production, 45, 9-19. https://doi.org/10.1016/j. jclepro.2012.07.007.

Bouwman, H., Haaker, T., \& De Vos, H. (2008). Mobile service innovation and business models. Heidelberg: Springer.

Bouwman, H., Heikkilä, J., Heikkilä, M., Leopold, C., \& Haaker, T. (2018). Achieving agility using business model stress testing. Electronic Markets, 28(2), 149-162. https://doi.org/10.1007/ s12525-016-0243-0.

Chatterjee, S. (2013). Simple rules for designing business models. California Management Review, 55(2), 97-124. https://doi.org/10. 1525/cmr.2013.55.2.97.

Chesbrough, H., \& Rosenbloom, R. S. (2002). The role of the Business Model in capturing value from innovation: evidence from Xerox Corporation's technology spin-off companies. Industrial and Corporate Change, 11(3), 529-555. https://doi.org/10.1093/icc/11. 3.529 . 
Christensen, C. M., Bartman, T., \& Van Bever, D. (2016). The hard truth about business model innovation. MIT Sloan Management Review, $58(1), 31-40$.

Cosenz, F., \& Noto, G. (2018). A dynamic business modelling approach to design and experiment new business venture strategies. Long Range Planning, 51(1), 127-140. https://doi.org/10.1016/j.lrp. 2017.07.001.

Cummings, J. L., \& Holmberg, S. R. (2012). Best-fit alliance partners: The use of critical success factors in a comprehensive partner selection process. Long Range Planning, 45(2-3), 136-159. https://doi. org/10.1016/j.lrp.2012.01.001.

Daas, D., Bouwman, H., Overbeek, S., \& Hurkmans, T. (2013). Developing a decision support system for business model design. Electronic Markets, 23(3), 251-265. https://doi.org/10.1007/ s12525-012-0115-1.

Demil, B., \& Lecocq, X. (2010). Business model evolution: In search of dynamic consistency. Long Range Planning, 43(2-3), 227-246. https://doi.org/10.1016/j.lrp.2010.02.004.

De Reuver, M., Bouwman, H., \& Haaker, T. (2013). Business model roadmapping: A practical approach to come from an existing to a desired business model. International Journal of Innovation Management, 17(01), 1340006. https://doi.org/10.1142/ s1363919613400069.

Dubosson-Torbay, M., Osterwalder, A., \& Pigneur, Y. (2002). Ebusiness model design, classification, and measurements. Thunderbird International Business Review, 44(1), 5-23.

Ebel, P., Bretschneider, U., \& Leimeister, J. M. (2016). Leveraging virtual business model innovation: A framework for designing business model development tools. Information Systems Journal, 26(5), 519 550. https://doi.org/10.1111/isj.12103 .

El Sawy, O. A., \& Pereira, F. (2013). Business modelling in the dynamic digital space; an ecosystem approach. Springer.

Fielt, E. (2013). Conceptualising business models: Definitions, frameworks and classifications. Journal of Business Models, 1(1), 85105

Foss, N. J., \& Saebi, T. (2017). Fifteen years of research on business model innovation: How far have we come, and where should we go? Journal of Management, 43(1), 200-227. https://doi.org/10. $1177 / 0149206316675927$.

George, G., \& Bock, A. J. (2011). The business model in practice and its implications for entrepreneurship research. Entrepreneurship Theory and Practice, 35(1), 83-111. https://doi.org/10.1111/j. 1540-6520.2010.00424.x.

Haaker, T., Bouwman, H., Janssen, W., \& de Reuver, M. (2017). Business model stress testing: A practical approach to test the robustness of a business model. Futures, 89, 14-25. https://doi.org/10. 1016/j.futures.2017.04.003.

Hakkarainen, K., \& Talonen, T. (2012). Business model Roadmapping-a Practitioner's approach. In ISPIM Conference Proceedings (p. 1). The International Society for Professional Innovation Management (ISPIM).

Heikkilä, M., Saarni, J., Kaartemo, V., \& Koponen, A. (2015). Viability radar: A practical tool for assessing the viability of transformative service innovations in a healthcare context. Technology Innovation Management Review, 5(5), 17-30. https://doi.org/10.22215/ timreview/895.

Heikkilä, M., \& Bouwman, H. (2018). Business model innovation in European SMEs-descriptive analysis of quantitative survey and case survey data. In BLED 2018 Proceedings, 4.

Heikkilä, M., Bouwman, H., \& Heikkilä, J. (2018). From strategic goals to business model innovation paths: An exploratory study. Journal of Small Business and Enterprise Development, 25(1), 107-128. https://doi.org/10.1108/jsbed-03-2017-0097.

Jonkers, H., Lankhorst, M. M., ter Doest, H. W., Arbab, F., Bosma, H., \& Wieringa, R. J. (2006). Enterprise architecture: Management tool and blueprint for the organisation. Information Systems Frontiers, 8(2), 63-66. https://doi.org/10.1007/s10796-006-7970-2.

Kaplan, R. S., \& Norton, D. P. (2008). The execution premium: Linking strategy to operations for competitive advantage. Harvard Business Press.

Kuk, G., \& Janssen, M. (2013). Assembling infrastructures and business models for service design and innovation. Information Systems Journal, 23(5), 445-469. https://doi.org/10.1111/j.1365-2575. 2012.00418.x.

Lambert, S. C., \& Davidson, R. A. (2013). Applications of the business model in studies of enterprise success, innovation and classification: An analysis of empirical research from 1996 to 2010. European Management Journal, 31(6), 668-681. https://doi.org/10.1016/j. emj.2012.07.007.

Lankhorst, M. (2009). Enterprise architecture at work (Vol. 352). Berlin: Springer.

Latora, A. G., Compagno, L., \& Trapani, N. (2018). A decision support tool for business models analysis. International Journal of the Analytic Hierarchy Process, 10(2).

Lindgren, P., \& Rasmussen, O. H. (2013). The business model cube. Journal of Multi Business Model Innovation and Technology, 1(3), 135-182. https://doi.org/10.13033/ijahp.v10i2.516.

Morris, M., Schindehutte, M., \& Allen, J. (2005). The entrepreneur's business model: Toward a unified perspective. Journal of Business Research, 58(6), 726-735. https://doi.org/10.1016/j.jbusres.2003. 11.001.

Onetti, A., Zucchella, A., Jones, M. V., \& McDougall-Covin, P. P. (2012). Internationalization, innovation and entrepreneurship: Business models for new technology-based firms. Journal of Management \& Governance, 16(3), 337-368. https://doi.org/10. 1007/s10997-010-9154-1.

Osterwalder, A. (2004). The business model ontology: A proposition in a design science approach. Lausanne: University of Lausanne.

Osterwalder, A., \& Pigneur, Y. (2010). Business model generation: A handbook for visionaries, game changers, and challengers. John Wiley \& Sons.

Osterwalder, A., Pigneur, Y., \& Tucci, C. 1. (2005). Clarifying Business Models: origins, present, and future of the concept. Communications of the Association for Information Systems, 16, 2-25. https://doi.org/ 10.17705/1CAIS.01601.

Porter, M. E. (1980). Competitive strategy: Techniques for analyzing industries and competitors. Competitive Strategy. New York: Free Press.

Remané, G., Hanelt, A., Tesch, J. F. and Kolbe, L. M. (2017). The Business Model Pattern Database: a Tool for Systematic BMI. International Journal of Innovation Management (IJIM), 21(1), 750004. https://doi.org/10.1142/S1363919617500049.

Schwarz, J., \& Legner, C. (2020). Business model tools at the boundary: Exploring communities of practice and knowledge boundaries in business model innovation. Electronic Markets. https://doi.org/ 10.1007/s12525-019-00379-2.

Solaimani, S., Itälä, T., \& Bouwman, H. (2015). Networked Enterprise business model alignment: A case study on smart living. Journal of Information Systems Frontiers. 17(4), 871-887.

Solaimani, S., Heikkilä, M., \& Bouwman, H. (2018). Business model implementation within networked enterprises: A case study on a Finnish pharmaceutical project. European Management Review, 15, 79-96. https://doi.org/10.1007/s10796-013-9474-1.

Sosna, M., Trevinyo-Rodriguez, R. N., \& Velamuri, S. R. (2010). Business Model Innovation through Trial-and-Error Learning: The Naturhouse Case. Long Range Planning, 43(1), 383-407. https:// doi.org/10.1016/j.lrp.2010.02.003.

Szopinski, D., Schoormann, T., John, T., Knackstedt, R., \& Kundisch, D. (2019). Software tools for business model innovation: Current state and future challenges. Electronic Markets. https://doi.org/10.1007/ s12525-018-0326-1. 
Taran, Y., Nielsen, C., Thomsen, P., Montemari, M., \& Paolone, F. (2015). Business model process configurations: A mapping tool for fostering innovation. In $R \& P$ Management Conference.

Täuscher, K., \& Abdelkafi, N. (2017). Visual tools for business model innovation: Recommendations from a cognitive perspective. Creativity and Innovation Management, 26(2), 160-174. https:// doi.org/10.1111/caim.12208.

Teece, D. J. (2010). Business Models, Business Strategy and Innovation. Long Range Planning, 43 (2-3), 172-194. https://doi.org/10.1016/j. lrp.2009.07.003.

Terrenghi, N., Schwarz, J., Legner, C., \& Eisert, U. (2017). Business model management: Current practices, required activities and IT support. In Internationale Tagung Wirtschaftsinformatik 2017.

Timmers, P. (1998). Business models for electronic markets. Electronic Markets, 8(2), 3-8. https://doi.org/10.1080/10196789800000016.

Tourish, D. (2019). Management studies in crisis: Fraud, deception and meaningless research. Cambridge University Press.

Veit, D., Clemons, E., Benlian, A., Buxmann, P., Hess, T., Kundisch, D., \& Leimeister, J. (2014). Business models. An information systems research agenda. Business \& Information Systems Engineering, $6(1), 45-53$.

Versteeg, G., \& Bouwman, H. (2006). Business architecture: A new paradigm to relate business strategy to ICT. Information Systems Frontier, 8(2), 91-102. https://doi.org/10.1007/s10796-006-7973-z.

Vuorinen, T., Hakala, H., Kohtamäki, M., \& Uusitalo, K. (2018). Mapping the landscape of strategy tools: A review on strategy tools published in leading journals within the past 25 years. Long Range Planning, 51(4), 586-605. https://doi.org/10.1016/j.lrp.2017.06.005.
Weill, P., \& Woerner, S. L. (2013). Optimizing your digital business model. MIT Sloan Management Review, 54(3), 71.

Weking, J., Hein, A., Böhm, M., \& Krcmar, H. (2020). A hierarchical taxonomy of business model patterns. Electronic Markets. https:// doi.org/10.1007/s12525-018-0322-5.

Wirtz, B. W., Pistoia, A., Ullrich, S., \& Göttel, V. (2016). Business models: Origin, development and future research perspectives. Long range planning, 49(1), 36-54. https://doi.org/10.1016/j.lrp. 2015.04.001.

Wirtz, B. W., Schilke, O., \& Ullrich, S. (2010). Strategic development of business models: Implications of the web 2.0 for creating value on the internet. Long Range Planning, 43(2-3), 272-290.

Wirtz, B., \& Daiser, P. (2017). Business model innovation: An integrative conceptual framework. Journal of Business Models, 5(1).

Zott, C., \& Amit, R. (2007). Business model design and the performance of entrepreneurial firms. Organization Science, 18(2), 181-199. https://doi.org/10.1287/orsc.1060.0232.

Zott, C., \& Amit, R. (2008). The fit between product market strategy and business model: Implications for firm performance. Strategic Management Journal, 29(1), 1-26. https://doi.org/ 10.1002/smj.642.

Zott, C., Amit, R., \& Massa, L. (2011). The Business Model: recent developments and future research. Journal of Management, 37(4), 1019-1042. https://doi.org/10.1177/0149206311406265.

Publisher's note Springer Nature remains neutral with regard to jurisdictional claims in published maps and institutional affiliations. 